\title{
HIV and adolescents' educational attainment in South Africa: Disentangling the effect of infection in children and household members
}

\author{
A S Fotso, ${ }^{1,3} \mathrm{PhD} ; 0$ Banjo, ${ }^{2} \mathrm{PhD} ; \mathrm{J} 0$ Akinyemi, ${ }^{3,4} \mathrm{PhD}$ \\ ${ }^{1}$ ICAP, Columbia University, New York, USA; and Department of Demography and Population Studies, School of Social Sciences and Public \\ Health, University of the Witwatersrand, Johannesburg, South Africa \\ ${ }^{2}$ Department of Demography and Social Statistics, Obafemi Awolowo University, Ile Ife, Nigeria \\ ${ }^{3}$ Department of Demography and Population Studies, School of Social Sciences and Public Health, University of the Witwatersrand, \\ Johannesburg, South Africa \\ ${ }^{4}$ Department of Epidemiology and Medical Statistics, College of Medicine, University of Ibadan, Nigeria
}

Corresponding author: A S Fotso (simofotsoarlette@yahoo.fr)

\begin{abstract}
Background. Many empirical studies have assessed the effect of adults' HIV infection on their livelihood. However, the effect of children's HIV status on their educational outcomes during adolescence has not been adequately investigated.

Objectives. The study aims to evaluate the effect of household members' HIV infection and that of children on their educational outcomes (school enrolment and progression) during adolescence.

Methods. Waves 1 to 4 of the South African National Income Dynamics Study panel data collected between 2008 and 2015 were used. Analytical samples contained data for 8835 adolescents aged 10-19 years. Analysis involved the use of descriptive statistics, logistic and linear regression as well as Oaxaca and Ransom decomposition methods.

Results. Of the study sample, 7176 were currently in school and 636 were not. HIV infection had no effect on adolescent school enrolment. Adolescent HIV infection significantly reduced their school progress index by about 8.41 . The explanatory variables explained $18 \%$ of the adolescents' school progress gap associated with HIV infection. The unexplained gap might have been attributable to stigmatisation and/or unobserved morbidity associated with adolescents' HIV infection.

Conclusion. Adolescent HIV infection affects their school progression. Education support should be targeted directly at HIV-infected children instead of targeting families with infected parents only.
\end{abstract}

S Afr J Child Health 2018;12(2 Suppl 1):S4-S9. DOI:10.7196/SAJCH.2018.v12i2.1512

The past 30 years have witnessed growing concern about HIV/ AIDS infection in sub-Saharan Africa generally and the southern African region in particular, where the highest rates of the epidemic are recorded to date. ${ }^{[1]}$ The prevalence of the disease has orphaned many children and adolescents and caused school dropouts owing to disrupted family structures resulting from parental HIV positivity and subsequent deaths. This impacts negatively on adolescents' physical, social and psychological welfare, inter alia. ${ }^{[2,3]}$ Given that the risk of school dropout is very high at the secondary level of education for adolescents generally, ${ }^{[4]} \mathrm{HIV}$ infection has been found to further intensify the threat to completion of secondary education for adolescents living in areas with higher incidences of HIV. A number of studies have established a link between AIDS orphanhood and school attendance among children and adolescents. ${ }^{[4-6]}$ Other studies have also established a link between parental HIV status and their perceptions of their children's school participation, ${ }^{[7]}$ and between children's and adolescents' HIV/AIDS status and behavioural, psychological and psychosocial problems. ${ }^{[2,8,9]}$

Children and adolescents affected by HIV/AIDS are often vulnerable to discrimination, deprivation, victimisation, forms of abuse and dropping out of school, among other issues. ${ }^{[4,5,9-11]}$ For example, Watkins et al. ${ }^{[4]}$ explored the perception of HIV/AIDSorphaned adolescents in South Africa about factors influencing their secondary school attendance. The findings showed that complex and interconnected risk factors that obstruct secondary education completion include sporadic changes of school, recurring household migration, forced employment, and poverty before and after parental death, among other factors. A similar study in
Zimbabwe by Pufall et al. ${ }^{[6]}$ showed that although HIV status did not impact negatively on the educational outcomes of children aged 6 - 17 years, HIV/AIDS-orphaned children had a lower likelihood of being in the appropriate grade for their ages. Also, Islam et al. ${ }^{[10]}$ in a review of literature on the contemporary experiences of children born or living in households affected by HIV, found that such children are likely to suffer social isolation which will probably impact negatively on their self-image and future life opportunities.

The reviewed studies have clearly demonstrated the negative effect of HIV/AIDS among parents or other household members on the educational outcomes of children and adolescents, yet none of these studies has been able to evaluate the effect of children's own HIV infection on their educational outcomes in adolescence. Based on life-cycle theories, numerous studies have shown that children's poor health, particularly during the first years of life, is likely to negatively affect their education. ${ }^{[12,13]}$ Assessing the effect of children's own HIV infection on their school enrolment and progression at the adolescent stage is therefore necessary to understand whether or not the pattern of influence of parental infection on adolescent educational outcomes differs from that of the children's own infection. The present study aims to evaluate the effect of HIV infection on educational outcomes at adolescence. More specifically, it aims to distinguish the effects of parental/ caregiver infection from those of children's own infection. South Africa, having the highest number of new HIV infection in the southern African region, ${ }^{[14]}$ is a suitable context for addressing these objectives. 


\section{Method \\ Data collection}

To address our research objectives, we used waves 1,2, 3 and 4 of the National Income Dynamics Study (NIDS). NIDS is a national panel survey conducted by the Southern Africa Labour and Development Research Unit (SALDRU) at the University of Cape Town (UCT) under the initiative of the Department of Planning, Monitoring and Evaluation (DPME). The first wave began in February 2008, waves 2 and 3 followed in 2010 and 2012 respectively, and wave 4 was conducted between September 2014 and August 2015.

\section{Sample}

Following the definition of the World Health Organization (WHO) which considered an adolescent as a person between 10 and 19 years of age ${ }^{[15]}$ our sample was limited to individuals who were in that age range at wave 4 . Thus, 8835 adolescents constituted our study sample. With respect to the main outcome, the sample size has over $80 \%$ statistical power.

\section{Outcome variables}

We analysed two educational outcomes. The first one is school attendance, a dummy variable taking the value of 1 if an adolescent was enrolled in school during wave 4 , and 0 if not. The second outcome variable is the school progression index measured as per Patrinos' and Psacharopoulos' formula. ${ }^{[16]}$

School progression $=\frac{\text { Number of year of education }}{\text { Age }-E} \times 100$

Given that in South Africa the age requirement at school entrance is 5 years, ${ }^{[17]} \mathrm{E}$ is 5 . Owing to the fact that NIDS data allow clear identification of the number of years of education completed only from grade $\mathrm{R}$ till 12 , the analyses with this variable involved those who reported no education and years of education completed until grade 12. This index allows adjustment of the number of years of education from a child's age. Hence, a school progression index $\geq 100$ means a good school progression, while a school progression $<100$ means some school delay.

\section{Independent variables}

The main explanatory variable of interest in the present study is HIV infection during childhood or early adolescence. It is a dummy variable taking the value of 1 if an adolescent reported an HIV infection during one of the previous waves of the survey (i.e. waves 1 to 3 ) while they were aged 0 to 14 . The control variables used were those found in the literature to influence the education of children affected by HIV/AIDS. ${ }^{[18,19]}$ These included the HIV status of the household head ( $\mathrm{HH}$ ) and of other members of the household; the individual characteristics of the adolescent, such as age, gender and whether they were orphans, in 2012; the living arrangement such as relationship to the $\mathrm{HH}$, the HH's age, gender and education; and the household size and monthly household expenditure divided by 100 000. As rural and urban areas were not part of the publicly released NIDS data, the regions have been grouped according to population density based on the census of 2011. ${ }^{[20]}$ We did not control for race in our estimation because almost all our sample of HIVpositive adolescents were black Africans (90\%).

\section{Data analysis}

We present means/proportions and standard deviation of both dependent and independent variables as part of univariate analyses. The outcome variables were captured in 2014/2015 (wave 4) and the independent variables before or in 2012 (waves 1, 2 or 3) to isolate a temporal effect. The association of independent variables with school enrolment was assessed using the chi-square test and $t$-test for comparison of means, while a Wald test of association was used to evaluate the association with school progression. The multivariate analyses were done using a logistic regression for the school enrolment outcome and linear regression model for the school progression index. To determine the relative contribution of the explanatory variables to enrolment and school progression in adolescence, decomposition was performed using the Oaxaca and Ransom methods. ${ }^{[21]}$ For all analyses, we adjusted for the NIDS design weight.

\section{Results}

As shown in the first column of Table 1 , only $92.2 \%$ of adolescents were in school in 2014/2015. The mean school progression was 86.81 . The $p$-value reported in column 4 shows that there was no significant association, at $10 \%$ level, between school enrolment and HIV status of the adolescent, $\mathrm{HH}$ and other family members. However, school attendance was significantly associated with age, father's survival, HH's education and household monthly expenditures. All the variables appeared to be significantly correlated to school progression except the HIV status of other family members and the HH's age and gender, as shown by the $p$-value in column 5 .

\section{HIV status}

Columns 1 and 2 of Table 2 show that HIV infection contracted on or before 2012 had no effect on adolescent school enrolment. Similarly, other household members' HIV infection did not affect their school attendance. The first and second columns of Table 3 show that HIV infection contracted during childhood or early adolescence reduced adolescents' school progression significantly, by an average of about 8.41. The HH's HIV infection also reduced adolescents school progression, but only by an average of 4.11 . However, once the other control variables were controlled for, the effect of the HH's HIV illness was no longer significant (column 2). In contrast, HIV infection of another household member had a positive effect (by an average of 2.64) on adolescents' school attainment.

\section{Adolescent individual characteristics}

Table 2 shows that as age increases, the odds of attending school decrease by $47 \%$. On the other hand, adolescents' age was associated with a slower school progression, while being female increased the latter by an average of 6.72. Parental survival appeared not to be significant.

\section{Living arrangements and geographical location}

The odds of being currently in school among adolescents living with a female $\mathrm{HH}$ were 2.19 times those living with a male $\mathrm{HH}$. Similarly, the odds of school attendance were 2.19 times higher for adolescents having a $\mathrm{HH}$ with secondary, higher or vocational education compared with those with a $\mathrm{HH}$ with no, or primary, education. Compared with children and grandchildren of $\mathrm{HHs}$, adolescents who were close relatives to the $\mathrm{HH}$ had a school progression 1.84 times higher. Adolescents with older and better educated HHs had a school progression higher by 0.10 and 5.54 times, respectively. An increase of the household size by 1 person was associated with a school progression decline of 0.18 times. An increase in the monthly expenditure of the household by R100 000 resulted in an augmentation of adolescents' school progression index by an average of 12.51. Compared with adolescents living in high population density areas, those living in middle and lower density areas have a school progression index lower by an average of 2.89 and 4.01 , respectively.

\section{Decomposition results}

The first panel of Table 4 shows that there was a difference of $3 \%$ in school enrolment between the HIV-negative and HIV-positive adolescents. However, this difference appears not to be significant, 
Table 1. Frequencies, percentages of categorical variables and means of continuous variables used in the study

\begin{tabular}{|c|c|c|c|c|c|}
\hline & \multirow{2}{*}{$\begin{array}{l}\text { Overall } \\
\% / \text { mean }(N) \\
(\mathrm{SD})^{\star}\end{array}$} & \multirow{2}{*}{$\begin{array}{l}\text { Not enrolled at } \\
\text { school } \\
\% / \text { mean } \\
(\mathrm{SD})\end{array}$} & \multirow{2}{*}{$\begin{array}{l}\text { Enrolled at } \\
\text { school } \\
\% / \text { mean (SD) }\end{array}$} & \multicolumn{2}{|c|}{ Tests } \\
\hline & & & & $\begin{array}{l}p \text {-value school } \\
\text { enrolment }\end{array}$ & $\begin{array}{l}p \text {-value school } \\
\text { progression }\end{array}$ \\
\hline \multicolumn{6}{|l|}{ Outcomes in 2014/2015 } \\
\hline Enrolled at school & \multicolumn{5}{|l|}{$92.20(7176)$} \\
\hline School progression & \multicolumn{3}{|l|}{$86.81(8835)(0.26)$} & & \\
\hline \multicolumn{6}{|l|}{ HIV status before 2014} \\
\hline Adolescent HIV-positive & $0.50(39)$ & 4.70 & 95.30 & 0.61 & 0.02 \\
\hline HH HIV-positive & $3.40(235)$ & 10.50 & 89.50 & 0.36 & 0.02 \\
\hline Another member HIV-positive & $4.62(422)$ & 10.80 & 89.20 & 0.14 & 0.88 \\
\hline \multicolumn{6}{|l|}{ Individual characteristics in 2012} \\
\hline Age & $14.50 / 8835(0.05)$ & $17.66(0.16)$ & $14.13(0.05)$ & 0.00 & 0.00 \\
\hline Female & $49.60 / 4455$ & 8.20 & 91.80 & 0.35 & 0.00 \\
\hline Mother alive & $88.20 / 5575$ & 7.10 & 92.90 & 0.17 & 0.00 \\
\hline Father alive & $76.20 / 4653$ & 6.50 & 93.50 & 0.00 & 0.00 \\
\hline \multicolumn{6}{|l|}{ Living arrangement in 2012} \\
\hline Relationship to $\mathrm{HH}$ & & & & 0.18 & 0.01 \\
\hline Child/grandchild & $72.20 / 5356$ & 7.20 & 92.80 & & \\
\hline Close relative & $11.80 / 1004$ & 8.50 & 91.50 & & \\
\hline Non-relative/far-relative & $16.10 / 2466$ & 9.50 & 90.50 & & \\
\hline $\mathrm{HH}$ age & $47.18 / 8835(0.28)$ & $46.42(1.08)$ & $47.15(0.29)$ & 0.51 & 0.56 \\
\hline HH female & $65.40 / 4537$ & 7.20 & 92.80 & 0.11 & 0.34 \\
\hline HH secondary/ higher/other & $57.60 / 4036$ & 6.30 & 93.70 & 0.00 & 0.00 \\
\hline Household size & $6.38 / 8835(0.06)$ & $6.57(0.21)$ & $6.35(0.06)$ & 0.32 & 0.02 \\
\hline Total expenditure $(100000)$ & $0.04 / 8835(0.00)$ & $0.03(0.00)$ & $0.04(0.00)$ & 0.02 & 0.00 \\
\hline \multicolumn{6}{|l|}{ Geographic characteristics in 2012} \\
\hline Province population density & & & & 0.56 & 0.00 \\
\hline High & $38.90 / 2917$ & 7.40 & 92.60 & & \\
\hline Middle & $31.90 / 2013$ & 7.30 & 92.70 & & \\
\hline Low & $29.20 / 2249$ & 8.60 & 91.40 & & \\
\hline Observations & 8835 & 636 & 7176 & & \\
\hline
\end{tabular}

and hence no decomposition was produced. HIV contracted during childhood and early adolescence resulted in a significant school progression index gap of 10.26 between the HIV-negative and HIV-positive children. The second panel shows that $18 \%$ of this gap was explained by the independent variables. The last panel displaying details of the decomposition shows that only $3 \%$ of the gap was explained by household members' HIV infection, $11 \%$ by adolescent individual characteristics, and $8 \%$ by living arrangements. Geographical location contributed to reducing this gap by $4 \%$. The main part of the gap (84\%) was unexplained, which might be attributable to discrimination towards HIV-positive adolescents, and also unobserved characteristics associated with their HIV infection.

\section{Discussion}

In the present paper, we provide empirical evidence of the effect of children's HIV infection on their educational outcomes at adolescence, with specific focus on school enrolment and school progression. The main findings are twofold: firstly, HIV-positive status among adolescents does not have any significant influence on school enrolment but negatively affects school progression; and secondly, the HIV status of household members played a minimal role in adolescents' school enrolment and progression.
These results re-echo the complex relationship between adolescents' HIV infection and educational outcomes, especially in resourceconstrained settings. ${ }^{[6]}$ The pattern of the relationship differed, depending on the outcome measures. ${ }^{[6]}$ The explanations for these results are not far-fetched. The negative impact of HIV positivity may not be obvious at the time of school enrolment, which may be the reason why there was no significant difference in enrolment between HIV-positive and HIV-negative adolescents. Also, differential school enrolment between HIV-positive and HIV-negative children could not have been expected because schools are not supposed to discriminate on the basis of HIV serostatus. Similarly, no parent or guardian would choose to keep their children from enrolling in schools because of suspected or confirmed HIV infection. ${ }^{[9]}$ Lack of effect of HIV positivity on school enrolment is a positive outlook in the fight against HIV stigma and discrimination; it implies that no child or adolescent will be kept out of school owing to HIV.

In contrast to enrolment, lower school progression attributable to HIV positivity is a source of concern for adolescents' educational and other developmental outcomes. Although a deeper understanding of the underlying explanations for this relationship is beyond the scope of the data we analysed, there are some clues from the literature. In the absence of adequate treatment coverage and nutritional interventions, HIV infection tends to negatively affect 
Table 2. Odds ratios from logistic regression of factors associated with school enrolment in 2014/2015

\begin{tabular}{|c|c|c|c|c|}
\hline & \multicolumn{2}{|c|}{ HIV variables adjusted } & \multicolumn{2}{|c|}{ All variables adjusted } \\
\hline & OR & 95\% CI & OR & 95\% CI \\
\hline \multicolumn{5}{|l|}{ Adolescent HIV status } \\
\hline Negative & Reference & & Reference & \\
\hline Positive & 2.028 & $(0.283-14.537)$ & 0.695 & $(0.097-4.983)$ \\
\hline \multicolumn{5}{|l|}{ HH HIV status } \\
\hline Negative & Reference & & Reference & \\
\hline Positive & 0.677 & $(0.314-1.461)$ & 0.560 & $(0.234-1.338)$ \\
\hline \multicolumn{5}{|l|}{ Another member's HIV status } \\
\hline All negative & Reference & & Reference & \\
\hline Another member positive & 0.687 & $(0.389-1.214)$ & 0.753 & $(0.411-1.378)$ \\
\hline Age & & & $0.533^{\ddagger}$ & $(0.446-0.638)$ \\
\hline \multicolumn{5}{|l|}{ Sex } \\
\hline Male & & & Reference & \\
\hline Female & & & 1.035 & $(0.720-1.488)$ \\
\hline \multicolumn{5}{|l|}{ Mother survival } \\
\hline Not alive & & & Reference & \\
\hline Alive & & & 0.813 & $(0.493-1.343)$ \\
\hline \multicolumn{5}{|l|}{ Father survival } \\
\hline Not alive & & & Reference & \\
\hline Alive & & & 1.267 & $(0.835-1.923)$ \\
\hline \multicolumn{5}{|l|}{ Relationship to the $\mathrm{HH}$} \\
\hline Child/grandchild & & & Reference & \\
\hline Close relative & & & 0.980 & $(0.582-1.650)$ \\
\hline Non-relative/far-relative & & & 0.713 & $(0.278-1.831)$ \\
\hline HH age 2012 & & & $1.019^{\dagger}$ & $(1.003-1.034)$ \\
\hline \multicolumn{5}{|l|}{ HH sex } \\
\hline Male & & & Reference & \\
\hline Female & & & $2.185^{\ddagger}$ & $(1.500-3.185)$ \\
\hline \multicolumn{5}{|l|}{ HH education } \\
\hline No education/primary & & & Reference & \\
\hline Secondary or higher & & & $2.186^{\ddagger}$ & $(1.331-3.590)$ \\
\hline Household size & & & 0.975 & $(0.931-1.023)$ \\
\hline Total expenditure (100 000) & & & 12.209 & $(0.224-666.290)$ \\
\hline \multicolumn{5}{|l|}{ Province population density } \\
\hline High & & & Reference & \\
\hline Middle & & & 0.832 & $(0.534-1.295)$ \\
\hline Low & & & 0.948 & $(0.616-1.460)$ \\
\hline Observations & 5450 & & 4896 & \\
\hline
\end{tabular}

the psychological development of children and adolescents; $;{ }^{[7]}$ the immediate effect of this would reflect in their school progression.

Further results from our decomposition analysis revealed that individual adolescent's characteristics, rather than living arrangement, played greater roles in explaining differences in school progression between HIV-positive and HIV-negative adolescents. The main individual characteristic was female gender, while secondary education by $\mathrm{HH}$ and total expenditure were important as part of the living arrangement. School progression was better for female adolescents and for those living in households where the HH had at least a secondary education. To foster gender equality, it is necessary to pay attention to school progression among male adolescents. Similarly, special attention needs to be paid to adolescents living in households headed by persons with education below secondary level. The proportion of unexplained differences in school progression may be attributed to other unmeasured variables, such as stigma, but we are cautious to label this as stigma.

Our analyses were affected by some limitations. The most notable is the length of time covered by the longitudinal data. A short space of time, such as 3 - 4 years, may not be adequate to unravel the longitudinal effect of HIV status on educational outcomes. Secondly, the prevalence of HIV in the study cohort is low, which may explain why some key variables were not statistically significant. These limitations notwithstanding, we have provided useful evidence on the relative contributions of HIV status of adolescents and household members to educational outcomes among adolescents.

\section{Conclusion}

The present paper aimed to evaluate the effect of HIV infection on adolescents' educational outcomes, by making a distinction between the effects of adolescents' own HIV infection contracted during 
Table 3. Linear regression of school progression in 2014/2015

\begin{tabular}{|c|c|c|c|c|}
\hline & \multicolumn{2}{|c|}{ HIV var. adjusted } & \multicolumn{2}{|c|}{ All var. adjusted } \\
\hline & Coefficient & 95\% CI & Coefficient & 95\% CI \\
\hline \multicolumn{5}{|l|}{ Adolescent HIV status } \\
\hline Negative & Reference & & Reference & \\
\hline Positive & $-8.425^{\dagger}$ & $(-16.153--0.696)$ & $-8.411^{\dagger}$ & $(-16.660--0.161)$ \\
\hline \multicolumn{5}{|l|}{ HH HIV status } \\
\hline Negative & Reference & & Reference & \\
\hline Positive & $-4.108^{\dagger}$ & $(-7.417--0.798)$ & -2.766 & $(-6.079-0.548]$ \\
\hline \multicolumn{5}{|l|}{ Another member HIV status } \\
\hline All negative & Reference & & Reference & \\
\hline Another member HIV-positive & 1.181 & $(-1.416-3.778)$ & $2.636^{\dagger}$ & $(0.068-5.204]$ \\
\hline Age & & & $-0.734^{\ddagger}$ & $(-0.927--0.540]$ \\
\hline \multicolumn{5}{|l|}{ Sex } \\
\hline Male & & & Reference & \\
\hline Female & & & $6.722^{\ddagger}$ & $(5.605-7.839)$ \\
\hline \multicolumn{5}{|l|}{ Mother survival } \\
\hline Not alive & & & Reference & \\
\hline Alive & & & 1.118 & $(-0.574-2.810)$ \\
\hline \multicolumn{5}{|l|}{ Father survival } \\
\hline Not alive & & & Reference & \\
\hline Alive & & & 1.049 & $(-0.204-2.301)$ \\
\hline \multicolumn{5}{|l|}{ Relationship to the $\mathrm{HH}$} \\
\hline Child/grandchild & & & Reference & \\
\hline Close relative & & & $1.839^{\dagger}$ & $(0.390-3.288)$ \\
\hline Non-relative/far-relative & & & -0.083 & $(-2.408-2.242)$ \\
\hline HH age & & & $0.103^{\ddagger}$ & $(0.059-0.147)$ \\
\hline \multicolumn{5}{|l|}{ HH sex } \\
\hline Male & & & Reference & \\
\hline Female & & & 0.274 & $(-1.001-1.549)$ \\
\hline \multicolumn{5}{|l|}{$\mathrm{HH}$ education } \\
\hline No education/primary & & & Reference & \\
\hline Secondary or higher & & & $5.536^{\ddagger}$ & $(4.178-6.894)$ \\
\hline Household size & & & $-0.181^{\dagger}$ & $(-0.348--0.015)$ \\
\hline Total expenditure (100 000) & & & $12.505^{\ddagger}$ & $(4.660-20.350)$ \\
\hline \multicolumn{5}{|l|}{ Province population density } \\
\hline High & & & Reference & \\
\hline Middle & & & $-2.886^{\ddagger}$ & $(-4.307--1.464)$ \\
\hline Low & & & $-4.010^{\ddagger}$ & $(-5.329--2.691)$ \\
\hline Constant & $87.255^{\ddagger}$ & $(86.652-87.857)$ & $87.112^{\ddagger}$ & $(82.303-91.921)$ \\
\hline Observations & 5644 & & 5041 & \\
\hline
\end{tabular}

childhood and that of other household members. It appears that HIV infection has no significant effect on school enrolment among adolescents. However adolescents' own HIV infection is a cause of a significant gap in school progression. The HIV status of household members played a minimal role in adolescents' school enrolment and progression gap.

Future studies based on larger datasets and longer periods of followup are recommended to generate more robust evidence on the relationship between HIV status and educational outcomes.

Acknowledgements. The support of the DST-NRF Centre of Excellence in Human Development towards this research is hereby acknowledged. Opinions expressed and conclusions arrived at, are those of the authors and are not necessarily to be attributed to the CoE in Human Development. The authors gratefully acknowledge the support of the Demography and Population Studies Programme, Schools of Public Health and Social Sciences, Faculties of Health Sciences and Humanities, University of the Witwatersrand, Johannesburg, South Africa.

Author contributions. ASF proposed the concept of this paper. OB provided data for the study and performed the literature review. ASF analysed the data in consultation with JOA and interpreted the data. JOA discussed the results. All the authors reviewed and approved all versions of the manuscript.

Funding. None.

Conflicts of interest. None. 
Table 4. Oaxaca decomposition of significant educational gap between HIV-negative and HIV-positive adolescents

\begin{tabular}{|c|c|c|c|c|}
\hline & \multicolumn{2}{|c|}{ School enrolment } & \multicolumn{2}{|c|}{ School progression } \\
\hline & Proportions & SE & Mean & SE \\
\hline HIV-negative & 0.92 & 0.01 & 87.36 & 0.31 \\
\hline HIV-positive & 0.95 & 0.05 & 77.09 & 3.75 \\
\hline Difference & -0.03 & 0.05 & $10.26^{*}$ & 3.76 \\
\hline Explained & & & $1.85^{\dagger}(18 \%)$ & 1.12 \\
\hline Unexplained & & & $8.41^{*}(82 \%)$ & 3.79 \\
\hline \multicolumn{5}{|l|}{ Explained by } \\
\hline HIV status household members & & & $0.27(3 \%)$ & 0.88 \\
\hline Individual characteristics & & & $1.09(11 \%)$ & 0.79 \\
\hline Household arrangement & & & $0.86(8 \%)$ & 0.66 \\
\hline Geographical characteristics & & & $-0.37(-4 \%)$ & 0.55 \\
\hline $\begin{array}{l}\mathrm{SE}=\text { standard error. } \\
\text { Significance levels: }{ }^{*} p<0.05 ;{ }^{\dagger} p<0.1 . \\
\% \text { indicates the proportion of the mean sc }\end{array}$ & 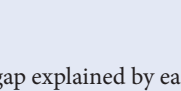 & & & \\
\hline
\end{tabular}

1. UNAIDS. Global AIDS Update. Geneva: UNAIDS; 2016. http://www.unaids.org/ sites/default/files/media_asset/global-AIDS-update-2016_en.pdf. (accessed 15 February 2018).

2. Bezuidenhoudt C, Elago H, Kalenga E, Klazen S, Nghipondoka K, Ashton D. The psychological impact of HIV/AIDS: People are more than statistics. Future Lead Summit 2011;18-2. https://org.elon.edu/summit/essays/essay4.pdf (accessed 15 February 2018)

3. Fortson JG. Mortality risk and human capital investment: The Impact of HIV/ AIDS in Sub-Saharan Africa. Rev Econ Stat 20011;93(1):1-15.

4. Watkins JA, Sello OM, Cluver L, Kaplan L, Boyes M. 'At school I got myself a certificate': HIV/AIDS orphanhood and secondary education: A qualitative study of risk and protective factors. Glob Soc Welf 2014;1(3):111-121.

5. Gillespie S, Norman A, Finley B. Child vulnerability and HIV/AIDS in subSaharan Africa : What we know and what can be done. IFPRI Work Pap 2005;34.

6. Pufall EL, Nyamukapa C, Eaton JW, et al. The impact of HIV on children's education in eastern Zimbabwe. AIDS Care 2014;26(9):1136-1143.

7. Grant MJ. Children's school participation and HIV/AIDS in rural Malawi: The role of parental knowledge and perceptions. Demogr Res 2008;19(45):1603-1634.

8. Mpango RS, Kinyanda E, Rukundo GZ, Levin J, Gadow KD, Patel V. Prevalence and correlates for ADHD and relation with social and academic functioning among children and adolescents with HIV/AIDS in Uganda. BMC Psychiatry 2017;17(1):336.

9. Sherr L, Cluver LD, Betancourt TS, Kellerman SE, Richter LM, Desmond C. Evidence of impact: Health, psychological and social effects of adult HIV on children. AIDS Lond Engl 2014;28 (Suppl 3):S251-259.

10. Islam MS, Scott VM. Children living in HIV families: A review. J Child Adolesc Behav 2014;2(5):1-7.

11. Nyirenda M, McGrath N, Newell M-L. Gender differentials in the impact of parental death: Adolescent's sexual behaviour and risk of HIV infection in rural South Africa. Vulnerable Child Youth Stud 2010;5(3):284-296.
12. Case A, Fertig A, Paxson C. The lasting impact of childhood health and circumstance. J Health Econ 2005;24(2):365-389.

13. Fotso AS, Solaz A, Diene M, Nanfosso RT. Human capital accumulation of children in Cameroon: Does disability really matter? Educ Econ 2018;26(3):305-320.

14. UNAIDS. Ending AIDS: Progress towards the 90-90-90 targets. Geneva: UNAIDS, 2017. http://www.unaids.org/sites/default/files/media_asset/Global_ AIDS update 2017 en.pdf (accessed 15 February 2018).

15. Dehne K, Riedner G. Sexually transmitted infections among adolescents: The need for adequate health services. Geneva: World Health Organization; 2005. http://www.who.int/maternal_child_adolescent/documents/9241562889/en/ (accessed 16 October 2017).

16. Patrinos HA, Psacharopoulos G. Family Size, schooling and child labor in Peru: An empirical analysis. J Popul Econ 1997;10(4):387-405.

17. Department of Basic Education South Africa. Admission of learners to public schools. https://www.education.gov.za/Informationfor/ ParentsandGuardians/SchoolAdmissions.aspx (accessed 26 October 2017).

18. Kasirye I, Hisali E. The socioeconomic impact of HIV/AIDS on education outcomes in Uganda: School enrolment and the schooling gap in 2002/2003. Int J Educ Dev 2010;30(1):12-22.

19. Guo Y, Li X, Sherr L. The impact of HIV/AIDS on children's educational outcome: A critical review of global literature. AIDS Care 2012;24(8):9931012.

20. Statistics South Africa (SSA). Census 2011: Census in Brief. Pretoria: SSA; 2012.

21. Oaxaca RL, Ransom MR. On discrimination and the decomposition of wage differentials. J Econom 1994;61(1):5-21.

Accepted 7 June 2018. 